\title{
APRESENTAÇÃO
}

\section{O FAZER ENUNCIATIVO DIANTE DE DESAFIOS SOCIAIS CONTEMPORÂNEOS: COMO DISCURSOS POLITICOS E SOCIAIS PASSARAM A SER MOLDADOS}

Em face a desafios contemporâneos que nos levam a questionar valores e direitos fundamentais, deve-se reiterar vigilância e se ampliar discussóes. $\mathrm{O}$ silenciamento não é uma opção para o cidadão consciente, menos ainda para a intelectualidade. Em um momento de acirramento de discursos em circulação nas instâncias política e social, emergiu a urgência de se colocar na centralidade do presente dossiê as discussóes sobre origens, perspectivas e o papel da academia diante do enfraquecimento de estruturas lastreadas em cientificidade.

A ascendência da descrença no fazer científico e no respeito à alteridade e à diversidade nos impulsionaram a convocar pensadores a contribuir com o debate. Para tanto, não seria coerente optar por uma abordagem científica em detrimento de outras. Em função disso, priorizando a multiplicidade de visóes, propusemos uma perspectiva multidisciplinar.

Inquietava-nos a oficialização, inclusive por parte de chefes de Estado, de discursos coloniais e colonizadores em um período em que a decolonização era escancarada, em que valores democráticos pareciam inegociáveis.

Enxergamos no pensamento de Boaventura Sousa Santos (1996) uma atualização no seu conceito de "epistemicídio" - posteriormente usado por outros pensadores, como Sueli Carneiro (2005) e Djamila Ribeiro (2017) - para demarcar uma tentativa de apagamento de sujeitos, de conhecimentos, de existência e de fazeres, numa intenção reiterada de se propor revisionismos históricos de toda natureza.

Tal contexto de esgarçamento marca o surgimento da remodelada (ou nem tanto) extrema direita pelo mundo, caracterizada por discursos tônicos, proliferação de fake news, reforço da subalternização de grupos historicamente mantidos 
à margem e que começavam a ganhar ligeiro espaço social em um contexto em que se passava a discutir mais frontalmente a efetiva inclusão.

Tudo ruiu com a não aceitação do outro, legitimada por discursos sociais e políticos. Não apenas passamos a assistir à emergência de vozes políticas intolerantes e preconceituosas, como tal fenômeno se escancarou ao nosso lado, personificado e figurativizado em atores sociais que integram e compóem nossa [co] existência afetiva no mundo: parentes, amigos, vizinhos. Surge, nas palavras de Yascha Mounk (2019), a ideia de democracias iliberais.

Pensar não apenas no enfrentamento, mas na compreensão e na ação diante de acontecimentos que nos atingiram como um assomo irruptivo passou a ter protagonismo nas rodas de conversa e nos estudos dos discursos, da Semiótica, das Relaçôes Internacionais, da Ciência Política, das Ciências Sociais e Jurídicas.

Nossa coletânea se inicia com uma entrevista de um dos mais proeminentes, quiçá o maior, nome da Semiótica de herança francesa: Diana Luz Pessoa de Barros é conhecida entre os estudiosos dos textos no Brasil e no mundo e ajuda a refletirmos sobre as estruturas que compóem e sustentam tais enunciados, fomentando sua compreensão e instigando o debate, dando prosseguimento a pesquisas desenvolvidas por ela sobre estudos intolerantes, o que vem realizando nos últimos anos com afinco. A entrevista foi concedida a Fernando Moreira e a Joyce Lopes e enfoca a diferença e a alteridade como fontes do nascedouro de discursos dessa natureza.

Em seguida, temos a grata satisfação de contar com um batalhão de frente da mais elevada patente e de inquestionável estofo. Os sete artigos que compóem a seção de contribuiçóes especiais são assinados por intelectuais de envergadura.

Começamos com o ilustre analista do discurso, mundialmente reconhecido, Dominique Maingueneau. O professor da Sorbonne, na França, defende em seu trabalho que os movimentos designados como "ascensão do populismo", "movimentos antissistema” etc. não devem ser entendidos apenas como rupturas sociais, mas, também e, essencialmente, discursivas. É a partir do discurso que os populistas tentam legitimar o que reivindicam: a tomada de posição que, na alegação deles, foi-lhes interditada. Esse discurso, até então restrito a ambientes de pouca reverberação, começa a cobrar amplificação, acusando uma parcela da sociedade como tendo o monopólio do lugar de fala. Tal amplificação se dará por meio de redes sociais, em que as assimetrias discursivas passam a se chocar frontalmente e a legitimação se dá de forma mais marcada quanto for maior a ruptura entre as narrativas, cada lado, assim, legitimando-se a partir da deslegitimação do outro, acirrando disparidades entre polos contrários. O texto é apresentado em francês. 
Em seguida, trazemos a tradução para o português de um recentíssimo trabalho publicado na França, na Actes Semiótiques, de um dos nomes mais cultuados da Semiótica mundial, Jacques Fontanille, parceiro de Algirdas Julien Greimas em obras como Semiótica das Paixóes (1993 [1991]) e de Claude Zilberberg em Tensão e Significação (2001 [1998]). A tradução foi feita pelo próprio Fontanille, em parceria com Fernando Moreira e Kati Caetano. Fontanille parte da ideia da ausência de uma definição muito bem definida do conceito de "populismo", o que náo impede que se entenda sua ideia geral, aliás, o professor da Universidade de Limoges, também na França, nos explica que é justamente essa ausência de uma definição estabilizada e pacificada que nos permite depreender seu sentido, advindo de outro conceito flutuante, o de "povo". O autor chama de "paixões tristes", precisamente: a desconfiança, a rejeição ao outro, o ódio etc., os componentes passionais presentes nesse conceito e sua hipótese é a de que tais paixôes funcionariam como atratores de temas e posiçóes políticos associados ao populismo.

Per Aage Brandt apresenta uma proposição ousada: a reflexão a respeito de uma semiótica planetária. O professor da Case Western Reserve University, dos Estados Unidos, apresenta o conceito de uma teoria da significação com base em uma "arquitetura estratificante que determina os níveis existentes de experiência social, tipos de funçóes de signos e funçóes semânticas na linguagem e, finalmente, os princípios mentais da subjetividade humana”. À tal relação, Brandt denomina "ecologia planetária da civilização", que seria constitutiva da semiótica humana. A reflexão é densa e abstrata, passível de uma grande interlocução com diversos segmentos científicos e favorecendo o estudo de contextos como o atual, em que as profusóes de sentidos se entrelaçam e se sufocam mutuamente. A arquitetura da diferenciaçáo ecológica de que trata Brandt se baseia na criação de três níveis em nossas relaçôes: orgânico, político e simbólico. O texto está em inglês.

A quarta contribuição é a da pesquisadora brasileira, atualmente professora da Universidade Paris 8, na França, Marcia Tiburi, que desenvolve uma densa discussão a respeito de um conceito sobre o qual ela trabalha em suas aulas na Universidade como resultado de pesquisa anterior que, inclusive, foi publicada em livro no Brasil. Em “'Ridículo político’: análise de uma mutação estético-política”, a autora trata da ideia de uma mutação que se estabelece em um patamar estético fundamental à política. O trágico como fundamento do político, segundo Tiburi, foi substituído pelo cômico. Sob essa ótica, a professora também trata da temática do fascismo nos processos eleitorais marcados pelo populismo, considerando o conceito de ridículo "por meio de uma análise do risível como forma psicopolítica de controle e de catarse sociais". 
Outra participação que muito nos honra e fortalece a discussão em elevado nível intelectual é a do diplomata aposentado, ex-ministro do Meio Ambiente e da Amazônia, ex-ministro da Fazenda, ex-professor da UnB e do Instituto Rio Branco, autor de diversos livros e ensaios sobre temas de história diplomática, desenvolvimento, Economia, Relaçóes Internacionais. Trata-se do destacado embaixador Rubens Ricupero que, a nosso pedido, gentilmente adaptou texto preparado para II ${ }^{a}$ Conferência Internacional de Humanidades (UFMG, UNESCO), o qual passa, agora, a ser publicado e, para a nossa satisfação, no presente dossiê por nós elaborado. No artigo, é feito um apanhado, por meio de relato pessoal do diplomata, do estado da arte no que tange à proteção aos direitos individuais no Brasil, aos coletivos, como os Direitos Humanos e ao meio ambiente, especialmente após a ascensão de Jair Bolsonaro ao poder.

A professora Sara Lagi, da Universidade de Turin, na Itália, assina o artigo "Some reflections on the importance of 'how to rule". As reflexôes sobre a questão de "como governar" e sobre "quem governa" são parte da discussão da política e dos limites ao governo para preservação de liberdades fundamentais. O texto da professora Lagi está em inglês.

Por fim, Zdzisław Wąsik, reitor sênior e professor da Philological School of Higher Education, em Wrocław, na Polônia, a partir de uma apresentação de conceitos de imagens do mundo, discutidos por correntes filosóficas, discorre sobre fenômeno e experiência das coisas do mundo e sobre a capacidade de interpretação e construção de mundos além das palavras, considerando o ser no mundo do sujeito em sua experiência de existência-no-mundo, termo inspirado no conceito de "ser-no-mundo" (MERLEAU-PONTY, 2015 [1945], p. 491). Após confrontação de teorias epistemológicas que versam sobre a complexidade do conhecimento científico do mundo e sua percepção fragmentada na cogniçáo psicofisiológica, é destacada como contribuição para o tema a apresentação de métodos de pesquisa sobre o mundo vivido ao lidar com a ideologia da promessa ou ameaça feita por líderes de movimentos sociais que oferecem uma esperança por mundos melhores que náo se apresentam atualmente, mas poderiam ser alcançados no futuro. Wąsik termina apontando propostas para abordar as relaçôes entre mundo e realidade em sua ordenação hierárquica e sua modelagem semiótica. O texto está em inglês.

Passando aos artigos do dossiê, os professores de Comunicação Social Duílio Fabbri Jr, do Unisal e do UniAnchieta, e Fabiano Ormaneze, do Metrocamp e do UniAnchieta e convidado da Extecamp-Unicamp, analisaram discursos durante o curtíssimo e polêmico período em que Luiz Henrique Mandetta esteve à frente do Ministério da Saúde em meio à pandemia do novo 
coronavírus. As análises em "O discurso nos limites da obediência: enunciados que afagam ou abafam conflitos entre Mandetta e Bolsonaro na crise do coronavírus" permitiram aos autores discussóes sobre democracia, autoritarismo e relações de poder que perpassam estratégias de desinformação.

Em "Crises econômicas, ascensão da extrema direita e a relativização dos direitos humanos", a doutora em Ciência Política pela UFSCar, Alessandra Guimarães Soares; a mestranda em Relaçóes Internacionais pela USP, Catharina Libório Ribeiro Simóes e o doutorando em Direito Internacional Público pela USP, Thiago Giovani Romero, avaliam a relação existente entre as crises financeiras, a ascensão da extrema direita e a relativizaçáo dos Direitos Humanos, especialmente, dos grupos minoritários.

Natália Silva Giarola de Resende, doutoranda em Linguística pela Universidade Federal de Minas Gerais (UFMG) e Conrado Moreira Mendes, professor do Programa de Pós-graduação em Comunicação Social da PUC Minas, analisam em “Totalitarismo em The Handmaid's Tale: entre manipulação e programação" o primeiro episódio da série, sob o ponto de vista da sociossemiótica, para, então, promoverem uma discussão mais abrangente sobre o Estado totalitário.

"Representações do imigrante boliviano; questôes enunciativas" traz as reflexôes do professor do Programa de Pós-graduação em Letras da Universidade Presbiteriana Mackenzie, Alexandre Marcelo Bueno, acerca da construção, pelos meios de comunicaçáo, da imagem do imigrante boliviano no Brasil e destaca a importância da reivindicação, por grupos minoritários, do protagonismo em suas próprias representatividades. Dessa maneira, não permaneceriam à mercê da construção de suas imagens por grupos dominantes.

Professor de Teoria da Constituição e Direito Constitucional da PUC Minas, o doutorando em Direito pela UFMG, Fernando Caetano, faz, a partir de conceitos de subalternidade (SPIVAK, 2015 [1985]) e de marginalidade Quijano (1978), uma importante discussão sobre a efetiva universalidade que a ideia de Sujeito de Direito deveria assegurar aos indivíduos. Tal contrato é quebrado, segundo o pesquisador, pela desigualdade construída e perpetuada socialmente, reproduzindo "estruturas de dominação que marginalizam e subalternizam sujeitos".

$\mathrm{O}$ artigo, escrito em inglês, "An analysis on paradoxical gender equality+ policies and the violence in Brazil", do mestre em Relaçóes Internacionais pela Goldsmiths, de Londres, Renan Souza, discute a extrema opressão à população LGBTQ+ no Brasil, país mais violento para esses indivíduos, e, também a violência contra as mulheres. Neste caso, os números permanecem alarmantes, 
inserindo o país na lamentável quinta colocação mundial. $\mathrm{O}$ artigo aponta que "por mais que tenha havido avanços no Brasil, a ascensáo de grupos conservadores e de ultradireita pode minar todo o progresso atingido nas últimas décadas, o que pode agravar ainda mais a problemática da violência de gênero no país”.

Mestranda no Programa de Pós-graduação em Sociologia da Universidade de Sáo Paulo (PPGS - FFLCH/USP), Mariana dos Santos Faciulli, debate o conceito de novo terrorista enquanto "uma construção política e epistêmica que se fundamenta sobre a produção histórica do Outro racial e serve de veículo à sua manutenção". Seu artigo é intitulado "Eles querem quebrar a mesa': terrorismo e diálogo".

Elizabeth Christina de Andrade Lima e Isabelly Cristiany Chaves Lima, respectivamente, Professora Titular de Antropologia e doutoranda no Programa de Pós-Graduação em Ciências Sociais, ambas da Universidade Federal de Campina Grande (PPGCS-UFCG), tratam de narrativas que envolveram a campanha eleitoral à Presidência da República no ano de 2018, abordando a aproximação de temas em princípio opostos, como família, medo e ódio. Ao longo do trabalho, apresentam e questionam conceitos conservadores na pretensa nova política.

Pesquisador em nível de mestrado no Programa de Pós-graduação em Semiótica e Linguística Geral, da FFLCH USP, Renato Albuquerque de Oliveira parte de Tristes Trópicos, de Lévi-Strauss (2016 [1955]) e se inspira em uma discussáo, presente na obra, no contexto de indivíduos da etnia Nambiquara, convidando à reflexão sobre um tema comum à nossa sociedade: o contrato político-veridictório.

César Santos, mestrando no Programa de Relaçóes Internacionais da Universidade Federal do ABC (UFABC), discute o esfacelamento das características de um Estado laico, como prevê a Constituição Federal. O pesquisador reflete sobre os efeitos de tal escolha a partir das mudanças orgânicas no Ministério das Relações Internacionais sob a orientação do Chanceler Ernesto Araújo. Nesse mesmo período, César Santos observa a quantidade de assassinatos de lideranças indígenas no Brasil causados, especialmente, pela ausência de demarcação das terras indígenas prevista na Constituição Federal de 1988. Para o autor, há uma urgente necessidade de construção de um paradigma indigenista na política externa brasileira.

Fechando a coletânea, temos a pesquisa "Populismo e fake news na era da pós-verdade: comparaçóes entre Estados Unidos, Hungria e Brasil”, em que a doutoranda no Programa de Pós-Graduação de Ciência Política da Universidade Federal do Rio Grande do Sul (PPGCP/UFRGS), Ana Julia Bonzanini Bernardi, 
e a mestranda em Ciência Política pelo Instituto Superior de Ciências Sociais e Políticas (ISCSP) da Universidade de Lisboa, Andressa Liegi Vieira Costa, investigam o uso de estratégias de desinformação e aspectos de cultura política nos três países escolhidos para a análise.

Esperamos que as leituras sejam aprazíveis e que possam inspirar o fortalecimento da ciência, paralelamente ao dos direitos universais que reforçam a pluralidade. Tais direitos nos são caros, muitos conquistados a preço de sangue, devendo permanecer irrevogáveis.

\section{Fernando Moreira}

Mestrando bolsista CNPq em Semiótica e linguística Geral pela Universidade de São Paulo (FFLCH USP), especialista em Relaçôes Internacionais (UnB) e Finanças (UBS - B3), integrante do grupo de estudos semióticos LabOres USP e do corpo editorial da revista Estudos Semióticos (USP); facilitador na Universidade Virtual do Estado de São Paulo (Univesp). Lattes: http://lattes. cnpq.br/7408859711434041. Orcid: http://orcid.org/0000-0001-8903-4415. E-mail: emaildofernandomoreira@gmail.com.

\section{Luciana Santana}

Professora de Ciência Política da Universidade Federal de Alagoas (Ufal), mestre e Doutora em Ciência Política pela Universidade Federal de Minas Gerais (UFMG) com sanduíche/Capes-DGU na Universidade de Salamanca, Espanha. Coordenadora do Curso Ciências Sociais/Licenciatura na modalidade EaD (Ufal). Coordenadora do Comitê de Ética em Pesquisa (CEP/Ufal). Vicepresidente do Fórum da Área de Ciências Sociais da UAB. Líder do grupo de pesquisa: Instituiçóes, Comportamento político e Democracia. Lattes: http:// lattes.cnpq.br/7338438190459190. Orcid: http://orcid.org/0000-0002-02031594. E-mail: lucianacfsantana@yahoo.com.br.

\section{REFERÊNCIAS}

CARNEIRO, A. S. A construçáo do outro como náo ser como fundamento do ser. 2005. 339f. Tese (Doutorado em Educação) - Faculdade de Educação, Universidade de São Paulo. São Paulo, 2005.

FONTANILLE, J.; ZILBERBERG, C. Tensão e Significação. Trad. Ivã Lopes, Luiz Tatit e Waldir Beividas. São Paulo: Humanitas: FFLCH/ USP, 2001 [1998]. 
GREIMAS, A. J.; FONTANILlE, J. Semiótica das Paixóes: Dos estados de coisas aos estados de alma. São Paulo: Ática, 1993 [1991].

LÉVI-STRAUSS, C. Tristes trópicos. Trad. Rosa Freire d'Aguiar. São Paulo: Companhia das Letras, 2016 [1955].

MERleAU-PONTY, M. Fenomenologia da Percepçáo. São Paulo: Martins Fontes, 2015 [1945].

MOUNK, Y. O povo contra a democracia: por que nossa liberdade corre perigo e como salvá-la. Trad. Cássio de Arantes Leite e Débora Landsberg. Sáo Paulo: Companhia das Letras, 2019.

QUIJANO, A. Notas sobre o conceito de marginalidade social. In: PEREIRA, L. (org.). Populaçóes marginais. São Paulo: Duas Cidades, 1978.

RIBEIRO, D. O que é lugar de fala?. Belo Horizonte: Letramento, 2017.

SOUSA SANTOS, B. de. Pela máo de Alice: o social e o político na pósmodernidade. Campinas: Cortez, 1996.

SPIVAK, G. Pode o subalterno falar?. Trad. Regina Goulart Almeida et al. Belo Horizonte: Ed. da UFMG, 2010 [1985]. 